\title{
Analysis and Management of Accounting Fraud in Listed Companies-Thoughts Based on the GREENCOOL Case
}

\author{
Xiaowei Zhou ${ }^{1}$, Yunyi Wang ${ }^{1}$ \\ ${ }^{1}$ International Business School Shaanxi Normal University Xi'an, Shaanxi
}

\begin{abstract}
With the continuous development of economic market, the importance of accounting information to listed companies is also increasing. However, at the same time, the phenomenon of accounting fraud is further deepened. This is a major blow to the smooth operation and further improvement of the world economy. Therefore, it is imperative to prevent and cure accounting fraud. This article analyzes the GREENCOOL case, agents the produces to the accounting fraud as the center, studies the cases of fraud methods and the reasons for the success of fraudsters, finally points out the harm it caused. It combines with the current economic situation in China, finds out the common environment accounting fraud, and puts forward targeted solutions to several key points. In the current environment, it has important practical significance.
\end{abstract}

\section{Introduction}

With the global economy grows faster, economic crimes have become increasingly rampant. In this general environment--Accounting fraud, the most prominent manifestation of economic problems, has almost peaked in recent years.

Accounting fraud is not profitable by fictitious accounting business and creating false data. Many listed companies even acquiesce in this behavior in pursuit of illegal interests. It not only caused the loss of credit in our country's capital market, but also seriously affected its economic status. Therefore, in-depth study of this phenomenon is imperative. This article mainly analyzes and thinks about the GREENCOOL case, finds out the signals and causes of accounting fraud, puts forward preventive measures, takes appropriate measures, and carries out timely prevention and treatment.

\section{Introduction of GREENCOOL Case}

\subsection{Introduction to related parties}

Guangdong Kelon Electric Co., Ltd. was founded in 1984. It specializes in refrigerators, air conditioners and other refrigeration appliances. Its market share and reputation are all outstanding in the industry. It became a state-owned enterprise through reform in 1992. In 1996 and 1999, shares were issued and successfully listed in Hong Kong and Shenzhen. Kelon has always focused on leading the technology, and has won the National Science and Technology Progress Award many times. Its core refrigeration technology is at the top level. It is no exaggeration to say that before the GREENCOOL case,
Kelon Electric was a model in the industry and a benchmark for success.

\subsection{Introduction to GREENCOOL Accounting Fraud}

GREENCOOL is registered in the name of Gu Chujun, the company has been operating for ten years. At this time, Kelon has always been in a leading position in the electrical industry. Therefore, at the beginning of GREENCOOL, it has become Gu Chujun's first goal. At that time, the domestic electrical industry had a steady growth trend in China and had a huge profit margin. However, with the influx of a large number of foreign brands, the market share of local companies gradually declined. Faced with increasing competitiveness, Gu Chujun has always been dissatisfied with the benefits of simply improving the level of technology, but sought high profits through fraud and other improper means.

After Gu Chujun completely acquired Kelon, he set up a private account within the company to deal with the abnormal capital transactions between Kelon and GREENCOOL. Afterwards, Kelon was forced to purchase GREENCOOL's refrigerant at a price many times higher than the market price, and the capital was reversed under the name of the investment between the parent and the subsidiary. In just a few years, Kelon created false financial reports by forging economic business and other means, creating a false situation of turning a profit into a profit, making the company's annual false increase in profits by nearly 100 million dollars. 


\section{Case study}

\subsection{Motivation analysis}

In the case of GREENCOOL, the bad results have already been brought about, but we cannot stop there, and should analyze the reasons in depth and find prevention methods. The related motivation theories are mainly the following: fraud iceberg theory, fraud triangle theory, GONE theory, fraud risk factor theory, etc ${ }^{[1]}$. The risk factor theory is based on the GONE theory and is further developed. It is also a relatively new theory, which is more in line with the current market environment. Therefore, this article will mainly use this theory for motivation analysis.

Table I Risk factor theory

\begin{tabular}{|c|c|}
\hline Fraud Risk Factor & Measurement Criteria \\
\hline \multirow{2}{*}{ Individual risk factor } & Moral character \\
\cline { 2 - 2 } & Motivation \\
\hline \multirow{2}{*}{ General risk factor } & Opportunities for fraud \\
\cline { 2 - 2 } & Fraud detection probability \\
\cline { 2 - 2 } & Fraud costs \\
\hline
\end{tabular}

\subsubsection{Analysis of Individual Risk Factors}

Individual risk factors are mainly composed of moral quality and motivation

The risk factor of moral quality refers to that the fraudsters do not have professional ethics, and lack of legal awareness. If the fraudsters are in the management and have moral defects, they will often require financial personnel to forge data to ensure their own interests when the business operation is not satisfied. In this case, even if the internal control is perfect, it can not be avoided. But this factor is completely subjective and difficult to quantify.

Motivation risk factor refers to the demand of fraudsters, accounting fraud as an improper accounting behavior must have its promotion conditions. This factor is divided into internal motivation and external motivation:

The internal motivation is mainly driven by the economy, and the main beneficiaries of listed companies are large shareholders and the company's management. The large shareholders are the main controllers and beneficiaries of the enterprise, and there is a lot of room for operation. They often take advantage of their holdings and use improper means to encroach on the rights of the company and small shareholders. Gu Chujun in this case is stealing the company's interests through methods such as mergers and acquisitions to satisfy one's own desires. However, because the operator is not the actual controller of the enterprise, he has an employment relationship with shareholders and directors. In order to achieve the expectations of the actual controller of the company and gain trust, he may achieve his goal through fraud. At the same time, there are also some operators who use their own power to falsify financial reports for their own personal gain. Although the purpose is different, the two form a community of interests invisible, and require other users of accounting information to bear the losses.

The external motives are mostly political factors. On the one hand, under today's market conditions, the state's support for leading enterprises makes the performance of enterprise managers linked to their related political interests. Therefore, enterprises must cherish feathers. On the other hand, the performance of large companies in a region is often a criterion for judging local government officials. Driven by political interests, corporate management is likely to adopt certain methods to meet government needs voluntarily or not.

\subsubsection{Analysis of General Risk Factors}

General risk factors are more macroscopic, mainly related to the overall organization of the enterprise, and are more controllable than individual risk factors. Among them, the opportunity risk factor mainly appears at the internal structure level, mostly due to imperfect internal control, and the internal structure has defects. The risk factor of fraud detection probability refers to the low probability of fraud detection. It may be caused by the concealment of fraudulent means, or it may be due to the limited independence of the certified public accountants in auditing, or the firm may choose not to report to collusion. The nature and degree of punishment risk factors are mainly because my country's accounting legal system is not perfect, the punishment is small and light, and the cost of fraud is greatly reduced.

\section{2 symptom analysis}

\subsubsection{Abnormal Financial Indicators}

On April 29, 2005, Kelon Electric's annual report showed a net loss of more than 60 million that year. But only in the previous year, it achieved an amazing performance of more than 200 million. This abnormal phenomenon is enough to attract attention.

Table II Financial status and operating results during the reporting period currency: RMB

\begin{tabular}{|c|c|c|c|}
\hline Project & \multicolumn{2}{|c|}{ Year } & Rate of Increase \\
\hline & 2003 & 2004 & $(\%)$ \\
\hline Total assets & $9,501,441,214$ & $\begin{array}{c}11,361,393,59 \\
7\end{array}$ & $19.58 \%$ \\
\hline $\begin{array}{c}\text { Shareholders' } \\
\text { equity }\end{array}$ & $2,808,730,941$ & $2,803,156,761$ & $-0.20 \%$ \\
\hline $\begin{array}{c}\text { Profit from } \\
\text { principal } \\
\text { operations }\end{array}$ & $1,684,544,880$ & $1,823,967,815$ & $8.28 \%$ \\
\hline Net profit & $202,180,248$ & $-64,160,206$ & $-132 \%$ \\
\hline $\begin{array}{c}\text { Cash } \\
\text { equivalents }\end{array}$ & $40,266,536$ & $290,628,826$ & $622 \%$ \\
\hline
\end{tabular}

Coincidentally, this kind of anomaly has also occurred in another typical deed of accounting fraud, the "Xinjiang Chalkis" fraud case: 
Table III Xinjiang Chalkis Gross Margin Comparison Table

\begin{tabular}{|c|c|c|c|c|}
\hline Year & 2008 & 2009 & 2010 & 2011 \\
\hline Gross Margin & $24.93 \%$ & $21.30 \%$ & $-8.27 \%$ & $1.96 \%$ \\
\hline
\end{tabular}

From the table, we can easily find that both Xinjiang Chalkisand GREENCOOL suffered substantial losses before and after the fraud occurred. The company's financial indicators can often reflect the realization and expectations of the company's business objectives. If an enterprise's financial indicators often have abnormal conditions, then they should be vigilant enough for the company. In particular, the longitudinal comparison data of the company's turnover and profit and loss, should pay more attention to us.

\subsubsection{Independent Third Parties Blame Each Other}

Andersen was the first collaborator of GREENCOOL. And for some reasons, Arthur Andersen withdrew from Hong Kong and replaced $\mathrm{PwC}$, but he gave this big list to Deloitte. This behavior has been confusing. Even more eye-popping is that in 2005, Deloitte also terminated its cooperation with Kelon. The accounting firm can be said to be an independent third party with a considerable degree of understanding of the enterprise's economic business. The similar vague attitudes of these well-known accounting firms can be said to be some hints of the Kelon crisis ${ }^{[2]}$.

\subsubsection{Abnormalities in Related Party Transactions}

Through Kelon's financial statements, we can find that the company's cash flow on the account is huge, accounting for more than half of its total assets, and it is as high as $74 \%$ of its net assets. The inventory value is also very high, even reaching 100 million. There are many specialpurpose entities in the company, and frequent transactions with related parties, but they are mainly cash, and the cash flow on the account is huge ${ }^{[3]}$.

Table IV Other receivables

\begin{tabular}{|c|c|c|}
\hline Year & $\begin{array}{c}\text { Parent company } \\
\text { financial statements }\end{array}$ & $\begin{array}{c}\text { Consolidated } \\
\text { Financial Statements }\end{array}$ \\
\hline 2003 & $1600,000,000$ & $130,000,000$ \\
\hline 2004 & $1700,000,000$ & $120,000,000$ \\
\hline
\end{tabular}

Comparing some of the financial statement items, it is not difficult to find that between Kelon and GREENCOOL often allocate funds arbitrarily without any business support, there are a large number of entrusted receipts and payments, this phenomenon of abnormal cash inflow and outflow between parent and subsidiary companies It is enough to prove that one of the parties conducts internal operations and infringes on the other party's funds in a large amount by means of related party transactions.

\section{Accounting fraud prevention measures}

Although the GREENCOOL case is a thing of the past, the discussion on it has not ended. The scandal directly caused Kelon's stock price to plummet, and the company also fell into stagnation. The harm of accounting fraud was evident. Therefore, we should draw lessons from this and draw the following revelations:

\subsection{Aspects of the company's internal environment}

\subsubsection{Improve corporate governance structure}

To reduce accounting fraud, we must first start with the enterprise itself. Among them, what should be placed first is the improvement of the company's internal governance structure ${ }^{[4]}$. The core of the company's internal governance structure is the power of supervision. In order to ensure the authenticity and validity of accounting information, it is necessary to ensure mutual restraint and supervision among various departments. This not only requires the company to give the board of directors, the board of supervisors and other relevant departments sufficient supervision power, but also must establish a supervision mechanism between these supervision departments to prevent cover-ups or supervision vacancies. In particular, the independence of these two departments, the board of supervisors and the board of directors, plays a vital role in ensuring effective supervision. Kelon lacked the mutual supervision of internal members, and finally caused a disaster. To ensure the normal operation of internal control, it is also necessary to ensure that the management and supervision functions are independent of each other, and that the company's internal audit department is independent of the management. This independence refers to the dual independence of economy and power. Only in this way can the internal audit system be justified and effective.

\subsubsection{Improve the transparency of corporate information}

Accounting fraud mainly focuses on the two situations of financial statement fraud and financial report fraud:

(a)Financial report fraud: China believes that financial report fraud refers to corporate management tampering and concealing accounting data, distorting and falsifying relevant data such as the company's balance sheet, and issuing financial accounting reports with a large amount of false information to guide Information users make wrong decisions.

(b) Fraud in financial statements: It is the intention of financial statement compilers to deliberately tamper with the key figures in financial reports in order to obtain private gain, so as to achieve the improper purpose of increasing the company's profits and increasing investor confidence. Such frauds mainly include: based on financial reports, forging and fictitizing related accounting transactions or voucher records; intentionally playing the relevant accounting standards, etc.

This shows that the prevention of accounting fraud must also strengthen the disclosure of accounting information. Open and transparent disclosure of true and 
effective relevant accounting information is one of the important duties of listed companies and an important performance of being responsible to stakeholders. This requires the joint efforts of the company itself and the industry. In my country, there are still many loopholes in the accounting information disclosure system, and the requirements for disclosure are not clear. Therefore, companies with special purposes often take advantage of this and provide low-quality information. This requires my country to clearly define the scope of disclosure, increase the disclosure of non-financial information such as production activities if necessary, improve the quality of information, reasonably divide the disclosure interval, strengthen its explanatory and usability, and prevent formalism.

\subsection{Aspects of the external environment of the company}

\subsubsection{Improve the moral quality of accounting practitioners}

Accounting personnel are always direct contacts of accounting information. In the current employment environment, it is difficult for accounting personnel to maintain their own identity. They often have to obey the hints of senior officials and act in violation of the regulations by the company's administrative intervention. This shows that the professional ethics of the accounting industry still needs to be improved. In the case of GREENCOOL, Gu Chujun alone cannot complete counterfeiting and must be helped by accountants. This requires us to start from the source, strengthen the entry assessment of practitioners, and purify the entire environment from the source. Secondly, the accounting industry should strengthen continuing education, strengthen professional ethics awareness, and adopt measures such as continuing re-education of accountants, regular training, and improvement of incentives, and take a multi-pronged approach. And companies should also consciously maintain the company's integrity, and carefully employ accounting personnel. In addition, a relevant moral evaluation system should be established to ensure the supervision of accounting personnel ${ }^{[5]}$.

\subsubsection{Improve relevant laws and regulations}

In recent years, China's economic aggregate and development rate have taken a leading position, but economic laws are still imperfect, the supervision of economic crimes is relatively backward, the punishment for economic crimes is too light, and the operability is not strong, which are all open for accounting fraud. In order to pursue improperly high profits, many listed companies have even gone on to imitate this illegal act, and the economic market has suffered greatly. In this case, some obvious unreasonable points were ignored, and afterwards, the punishment of the main offender was mainly based on administrative means such as fines, which did not play a deterrent role. Therefore, it is necessary to improve economic laws and regulations, increase punishment, learn from foreign laws and regulations, and greatly increase the opportunity cost of fraudsters, so as to kill fraud in the cradle.

\section{Conclusion}

This article focuses on the case analysis method, takes the typical "GREENCOOL" case as the material, and refers to the existing theories at home and abroad. It is found that under the environment of rapid economic development in China, accounting fraud is still a big problem that cannot be ignored. On the one hand, the imperfect domestic accounting system and the insufficient attack on economic crimes have become hotbeds for breeding fraud; on the other hand, the accounting industry has low entry barriers, the internal governance structure of listed companies is chaotic, and internal and external audits are not soundness and incomplete information disclosure also provide opportunities for potential fraudsters. In response to these problems, this article proposes relevant feasible measures to protect the interests of information users, standardizes the accounting market, avoids related violations of laws and regulations, maintains economic security, and ensures the stable operation of the economy. However, due to insufficient knowledge reserves, this article still has great limitations. In the future, we will continue to understand this problem and obtain more enlightenment according to the development of national conditions.

\section{Acknowledgements}

The first thing I can thank for being able to complete this article is my mentor, Professor Xiaowei Zhou. He put forward constructive opinions on the research direction of this article. In the writing process, he gave many useful pointers to the difficulties I encountered. Then I want to thank my friends. They have always encouraged and supported me. With the help of these people, I can stick to the end and express my sincere thanks to them!

\section{References}

1. Li Zhang, Huaxia $\mathrm{Hu}$, Yueyang Xu. Case Study of Financial Fraud Based on Fraud Triangle Theory[J]. Financial Monthly, 2015(07): 69-72.

2. Mingxia Hu. Analysis of Kelong's fraud cases: starting with cash flow indicators[J]. I nternational Business Accounting, 2014(05):41-45.

3. Jingqi Chen, Thinking about audit failure_-Based on the case analysis of Kelon Electric [J]. Accountant, 2016(11):57-58.

4. Sufen Zheng. Research on the Identification and Governance of Listed Companies' Financial Fraud [J]. Economic Research Guide. 2015(09):131-132.

5. Youqi Peng. Identification and Prevention of Accounting Fraud in Listed Companies[J]. Cooperative Economy and Technology, 2017(01):165-166. 